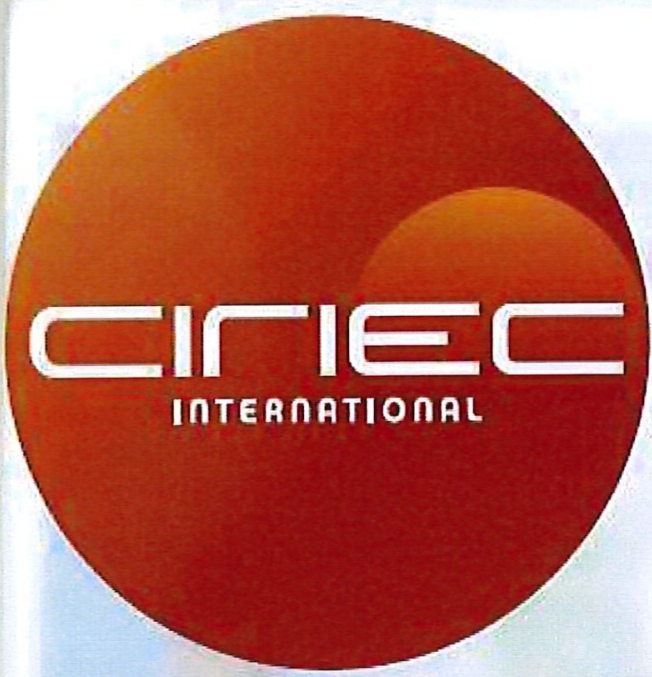

Working Paper

Evolución reciente de la economía social en la Unión Europea

Rafael CHAVES \& José Luis MONZÓN

CIRIEC N ${ }^{\circ} 2019 / 03$ 
CIRIEC activities, publications and researches are realised with the support of

Les activités, publications et recherches du CIRIEC sont réalisées avec le soutien de

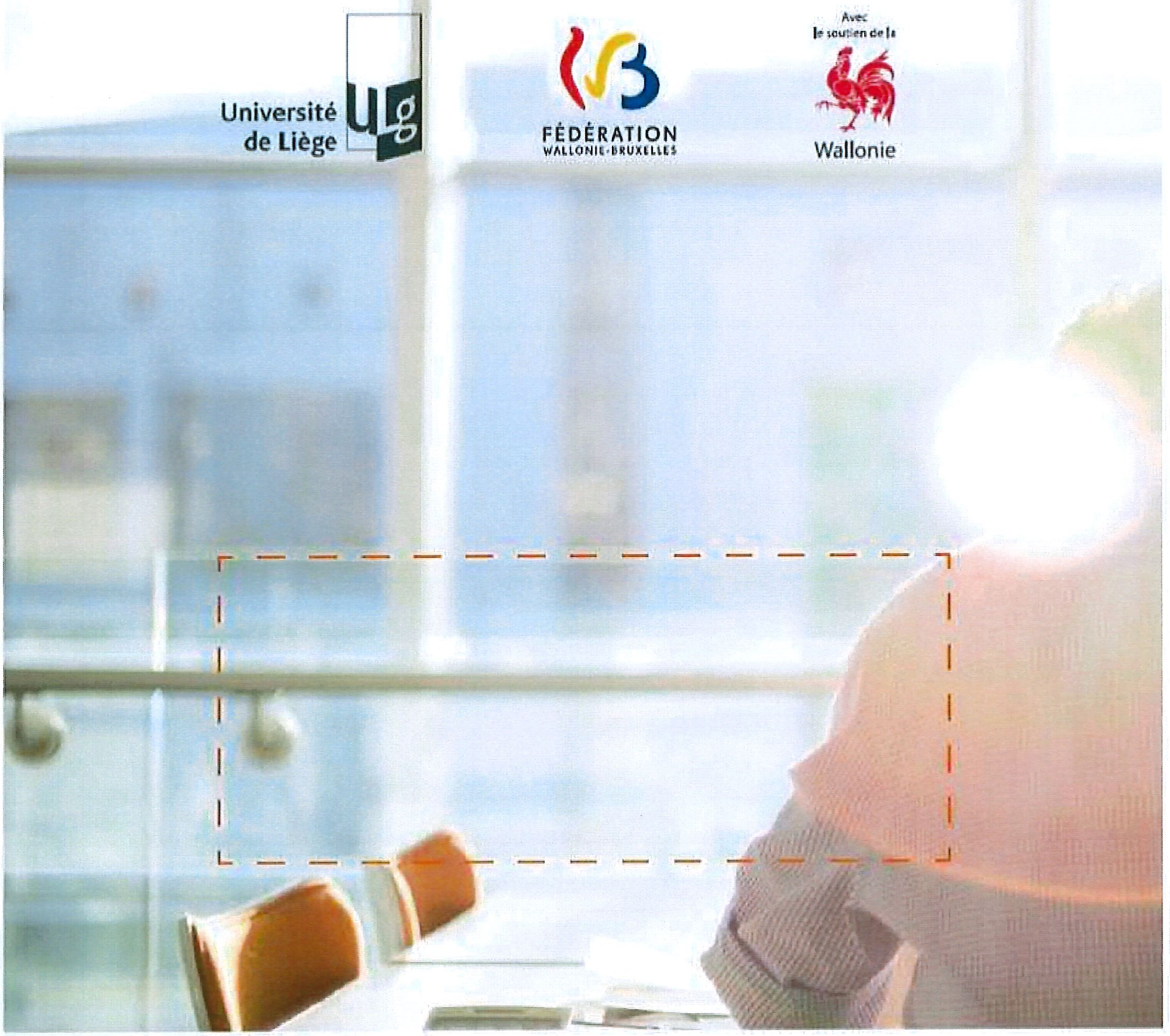


Evolución reciente de la economía social en la Unión Europea

Rafael Chaves y José Luis Monzón (dir.)*

Working paper CIRIEC N²019/03

\footnotetext{
* IUDESCOOP - Facultad de Economía, Universitat de València. Avda Tarongers, s/n, 46022 Valencia (España) (Email de contacto: Rafael.Chaves@uv.es)
} 



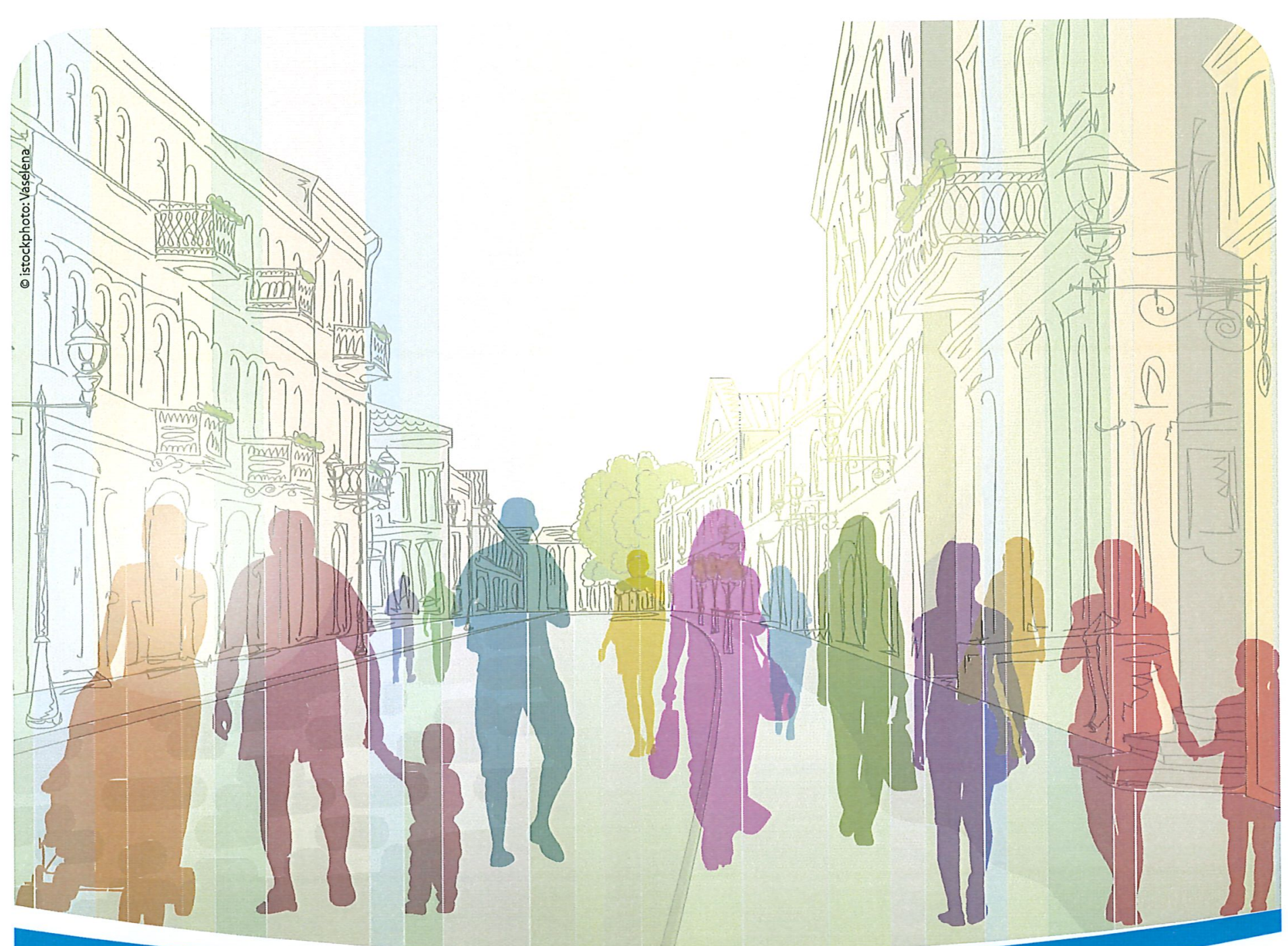

Evolución reciente

de la economía social

en la Unión Europea

RESUMEN

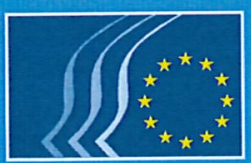

Comité Económico y Social Europeo 


\section{EXECUTIVE SUMMARY}

The general objective of the Report is to study the recent evolution of the social economy in the European Union. It focuses on three areas: firstly, the social economy and the emergent concepts/movements related to it, secondly, the public policies adopted in both the EU and the member states in recent years to enhance the social economy sector and thirdly, measuring the weight of the social economy in each EU member country.

This Report shows that the European social economy provides over 13.6 million paid jobs in Europe, accounting for $6.3 \%$ of the total EU working population of the EU-28. Despite its size, the social economy remains invisible in the national accounts and statistics around Europe, a hurdle that constitutes another major challenge, although efforts have been made during the last two decades.

The new concepts and approaches related to the social economy that have emerged in Europe, such as social enterprises, social innovation, collaborative economy, economy of the common good, circular economy and corporate social responsibility, have been analysed and the main public policies for the social economy that have been implemented in recent years have been studied. Special mention has been made of the Social Business Initiative (SBI) introduced by the European Commission. 


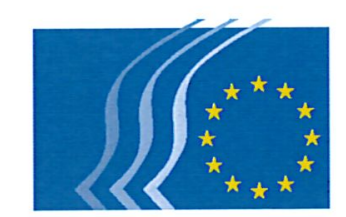

Comité Económico y Social Europeo

\title{
Evolución reciente de la economía social en la Unión Europea
}

\author{
$\underline{\text { Resumen }}$
}

La información y puntos de vista contenidos en este estudio son los de sus autores y no reflejan necesariamente la opinión oficial del Comité Económico y Social Europeo. El Comité Económico y Social Europeo no garantiza la exactitud de los datos recogidos en el estudio. Ni el Comité Económico y Social Europeo ni ninguna persona que actúe en su nombre podrán ser considerados responsables del uso que pudiera hacerse de la información contenida en el estudio. 


\section{SÍNTESIS}

\section{ÍNDICE}

Prólogo: Luca Jahier, presidente del Grupo de Actividades Diversas del Comité Económico y Social Europeo (CESE), Krzysztof Balon y Alain Coheur, coportavoces del Sector de Economía Social del CESE

1. Objetivos e introducción

2. EI concepto de economía social y los principales enfoques teóricos conexos

3. La economía social y los conceptos emergentes relacionados en Europa

4. Políticas públicas para la economía social a escala europea en los últimos años (2010-2016)

5. Políticas públicas para la economía social a escala nacional y regional en Europa en los últimos años (2010-2016)

6. El peso de la economía social en los 28 Estados miembros de la UE 


\section{PRÓLOGO de Luca Jahier}

Tengo el gran placer de dar la bienvenida a la publicación del estudio «Evolución reciente de la economía social en la Unión Europea», encargado por el Comité Económico y Social Europeo (CESE) y elaborado por el CIRIEC. Con la publicación de tres estudios sucesivos desde 2008, hemos demostrado nuestro continuo compromiso con el apoyo y la promoción de la economía social en Europa.

El estudio nos permite evaluar los progresos realizados, aportando datos fiables y comparables. Lo que es evidente es que la economía social ha salido en gran medida indemne de la crisis económica y financiera. En la actualidad, el sector da empleo al 6,3\% de la población activa en la Europa de los Veintiocho frente al 6,5\% en 2012.

Creo firmemente que la economía social refleja y defiende los valores sobre los que se ha construido la Unión Europea (artículo 3 del TUE). Es tanto una oportunidad como un vehículo para la participación ciudadana, la responsabilidad y propiedad de nuestro futuro sostenible. Además, constituye un ambicioso instrumento para que la UE pueda acercarse a sus compromisos en el marco de la Agenda 2030 de Desarrollo Sostenible de las Naciones Unidas.

Por este motivo, la creciente asistencia que la UE ha prestado a la economía social mediante el Fondo Social Europeo (FSE) resulta crucial. Me congratula especialmente que, a lo largo de los últimos años, las sucesivas Presidencias del Consejo de la UE hayan concedido prioridad a la economía social y hayan acogido favorablemente la contribución del CESE a su labor.

No obstante, aún queda mucho por hacer, como aumentar la visibilidad y el reconocimiento del sector. Espero sinceramente que en un futuro cercano se logren avances encaminados al desarrollo de estadísticas sistemáticas para los distintos grupos de la economía social y a la inclusión de la economía social en las cuentas estadísticas nacionales. Sin duda, esto supondría un primer paso necesario para dar a la economía social todo el crédito que se merece. Creo también que la vinculación de las dimensiones interior y exterior de la economía social de la UE reviste un enorme potencial sin aprovechar, especialmente en las relaciones con nuestros vecinos, en un momento de crecientes turbulencias políticas, económicas y de seguridad.

Pido a todos los agentes que aúnen esfuerzos y que redoblen sus actividades. Ya hemos conseguido grandes avances; sigamos juntos en este camino.

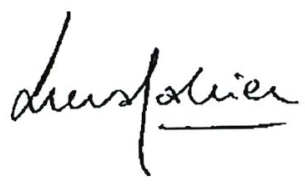

\section{Luca JAHIER}

Presidente del Grupo de Actividades Diversas Comité Económico y Social Europeo (CESE)

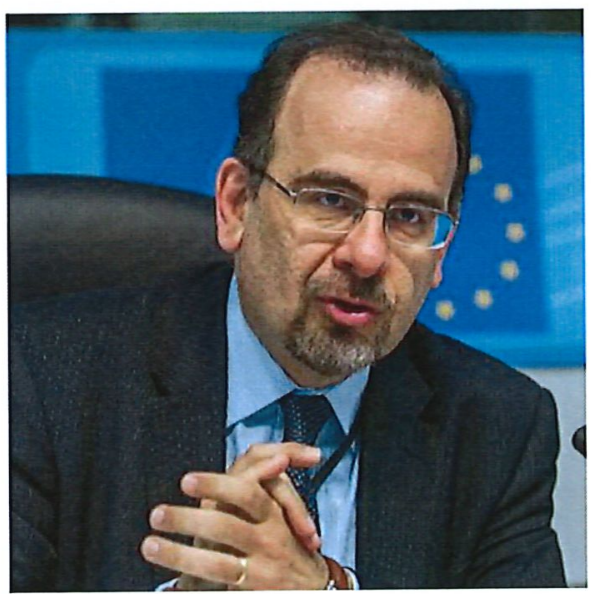




\section{PRÓLOGO de Alain COHEUR}

Esta es la tercera vez que el CESE publica un estudio sobre «Evolución reciente de la economía social en la Unión Europea», tras los llevados a cabo en 2008 y 2012. El estudio, encargado al centro de investigación CIRIEC, no supone una mera actualización de las versiones anteriores, sino que se centra en tres ámbitos:

- la economía social y los conceptos o movimientos emergentes,

- las políticas públicas en sentido amplio que se han desarrollado a escala de la UE y en los Estados miembros en los últimos años para mejorar el sector de la economía social,

- el tamaño de la economía social en cada uno de los Estados miembros de la UE.

Con la publicación del presente estudio, el CESE impulsa su compromiso por el reconocimiento y la promoción de la economía social, un sector que constituye una piedra angular esencial, no solo para el empleo y la cohesión social en toda Europa, sino también para la construcción y la consolidación de un pilar europeo de derechos sociales.

El estudio destaca el importante y creciente papel que desempeña la economía social en la economía de mercado, funcionando con ella y a su lado. Al garantizar que la eficiencia económica sirve a las necesidades sociales, la economía social crea una verdadera interdependencia entre las cuestiones económicas y sociales en lugar de subordinar una a la otra.

En numerosas ocasiones se ha puesto de relieve el potencial de crecimiento de la economía social en un momento de crisis económica y social. De hecho, la economía social constituye un modelo de resiliencia, que sigue desarrollándose mientras otros sectores económicos intentan salir a flote. No se trata de un subproducto: las empresas de la economía social reflejan la necesidad de una economía que aúne las dimensiones social, económica y financiera, que sea capaz de crear riqueza y que no se mida únicamente en términos de su capital financiero, sino también, y por encima de todo, de su capital social. Las actividades de las empresas de la economía social no están movidas únicamente por criterios de mercado o de crecimiento. El desarrollo, la rentabilidad de dos dígitos y los beneficios no son el objetivo en última instancia: la contribución al interés general, la cohesión social y el bienestar de nuestras sociedades sí lo son.

Este estudio demuestra que es esencial continuar debatiendo el concepto de empresa social, como parte de un plan más amplio y exhaustivo de apoyo, promoción y desarrollo de la economía social, de sus principios y de su gobernanza. También es vital impulsar el intercambio de buenas prácticas con otros Estados miembros que tengan amplia experiencia en la economía social.

El apoyo al crecimiento de la economía social requerirá mostrar coraje político con la adopción de medidas específicas en materia de fiscalidad, créditos y burocracia, y la adopción de medidas prácticas de apoyo a la economía social, especialmente para los jóvenes que desean participar en una economía más responsable e invertir en las personas.

El CESE seguirá siendo un aliado incondicional de las empresas de la economía social.

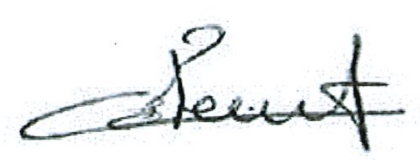

Alain COHEUR

Coportavoz del Sector de Economía Social

Comité Económico y Social Europeo (CESE)

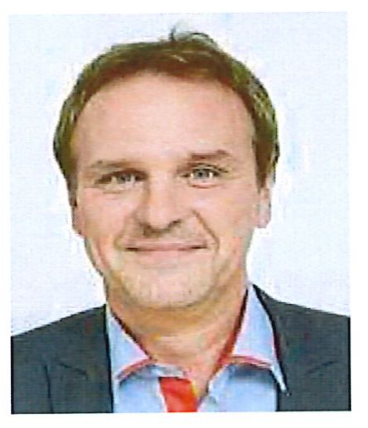




\section{PRÓLOGO de Krzysztof BALON}

La actual edición del estudio del CESE titulado «Evolución reciente de la economía social en la Unión Europea» confirma una vez más el importante papel del sector de la economía social a la hora de crear empleo, facilitar el crecimiento sostenible, ajustar los servicios a las necesidades y contribuir a un reparto más justo de la renta y la riqueza. No obstante, las actividades emprendidas por las empresas de la economía social abarcan un contexto mucho más amplio, como el refuerzo de la democracia participativa y del capital social. Esto se aplica especialmente a aquellos Estados miembros que se incorporaron a la UE a partir de 2004. La mayoría de ellos fueron, hasta 1989 o 1990, países socialistas bajo el dominio de la Unión Soviética, en los que las actuaciones de la sociedad civil eran muy limitadas o inexistentes. Las consecuencias de esta evolución histórica son, entre otras, una frágil situación financiera en el sector de las ONG y un bajo nivel de participación de la sociedad civil en la creación de oportunidades de empleo a escala local. Esto se puede ver incluso en las estadísticas: mientras que la tasa de empleo remunerado en la economía social es del 6,3\% en el conjunto de la UE, la misma tasa en los «nuevos» Estados miembros se sitúa de media en un 2,5\%.

Por otra parte, como reza el dicho ex oriente lux, de oriente también viene la luz: una gran cantidad de nuevas ideas y enfoques procedentes de estos países contribuyen a enriquecer la economía social europea. Desde la experiencia del movimiento polaco Solidarność/Solidaridad, pasando por los debates sobre la aplicación del principio de subsidiariedad, incluida la independencia de la economía social frente a las autoridades, hasta ejemplos prácticos, como el modelo eslovaco de empresas sociales municipales.

El diálogo permanente entre los legisladores y políticos y el sector de la economía social, tanto a escala nacional como europea, que comprenda experiencias de todos los Estados miembros, parece revestir una gran importancia para la creación de una estrategia a largo plazo de desarrollo de la economía social. Todos los agentes pertinentes están invitados a colaborar con el CESE para el reconocimiento de la economía social como una parte crucial —quizás dominante- del futuro modelo económico y social en Europa.

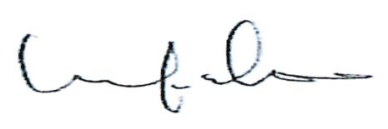

\section{Krzysztof BALON}

Coportavoz del Sector de Economía Social Comité Económico y Social Europeo (CESE)

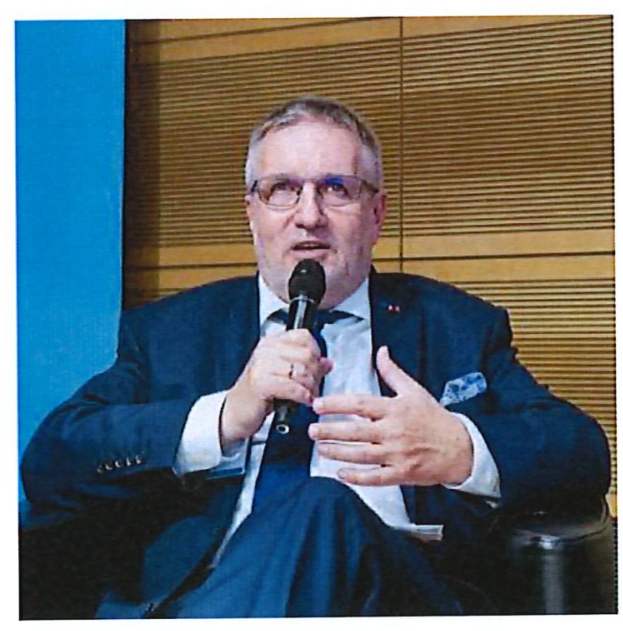

Copyright «Jan Brenner, dbb» 


\section{INTRODUCCIÓN Y OBJETIVOS}

\subsection{Objetivos}

El objetivo general del informe elaborado por el CIRIEC es estudiar la evolución reciente de la economía social en la Unión Europea (UE) y en sus 28 Estados miembros. Se centra en tres ámbitos: en primer lugar, la economía social y los conceptos o movimientos emergentes relacionados con el espacio entre los Estados y las empresas de mercado o con fines de lucro; en segundo lugar, las políticas públicas, en sentido amplio, construidas en la UE y en los Estados miembros en los últimos años para mejorar el sector de la economía social; y, por último, la medición del peso de la economía social en cada uno de los países miembros de la UE. Esta investigación no constituye una mera actualización de los estudios titulados «La economía social en la Unión Europea», elaborados por el CIRIEC y publicados en 2008 y en 2012 por el CESE, sino también un análisis y una evaluación de los cambios recientes producidos en este ámbito en Europa. Con el fin de ofrecer respuestas a los temas objeto de investigación, el proyecto se estructuró en tres ámbitos. En el primero de ellos, el ámbito conceptual, la investigación elaboró una síntesis de los conceptos emergentes, comparándolos con el concepto de economía social establecido en la UE, e identificando sus desafíos.

En el segundo ámbito, las políticas públicas, la investigación se centró en las políticas para la economía social que han desplegado las administraciones, a escala europea y nacional, en los últimos años (2010-2016). El entorno y el «ecosistema» de la economía social constituyen un importante factor que puede facilitar el desarrollo de entidades de la economía social o convertirse en un obstáculo exterior a las mismas. El proyecto formuló un marco para clasificar todas estas políticas. Ofrece un examen de las principales iniciativas desplegadas a escala nacional y de la UE, un análisis comparativo de la nueva legislación nacional sobre la economía social y una evaluación de sus repercusiones en Europa.

El tercer ámbito es el de la estadística. Su principal objetivo era ofrecer datos cuantitativos sobre la economía social en los 28 Estados miembros, siguiendo el mismo método utilizado en los dos estudios anteriores elaborados por el CIRIEC para el CESE. También estudiaba los recientes cambios en las estadísticas y los datos disponibles en toda Europa.

\subsection{Métodos}

El informe ha sido dirigido y elaborado principalmente por Rafael Chaves y José Luis Monzón del CIRIEC, con el asesoramiento de un comité de expertos que ha debatido con los directores la totalidad del calendario de trabajo, la metodología y el informe final propuesto, y les ha ayudado a identificar las distintas clases de empresas y organizaciones que forman parte de la economía social en cada uno de los países de la Unión Europea. 
Con respecto a los métodos en sí mismos, la primera parte del informe toma la definición del sector empresarial o del mercado de la economía social que aparece en el Manual para la elaboración de las cuentas satélite de las cooperativas y las mutualidades de la Comisión Europea, como base para establecer una definición de la economía social como conjunto que pueda lograr un amplio consenso político y académico.

En lo que respecta al segundo objetivo del informe, en marzo y abril de 2017 se llevó a cabo un importante estudio de campo mediante el envío de un cuestionario a los 28 Estados miembros de la UE. Se envió a testigos privilegiados que cuentan con conocimiento experto del concepto de la economía social y de los ámbitos conexos y de la realidad del sector en sus respectivos países. Estos expertos son investigadores universitarios, profesionales que trabajan en las federaciones y estructuras que representan a la economía social y altos funcionarios de las administraciones nacionales con responsabilidad relacionada con la economía social. Los resultados han sido extremadamente satisfactorios, ya que se han recabado 89 cuestionarios completos de los 28 países de la UE.

En lo que respecta al tercer objetivo inmediato del informe, la identificación de políticas públicas, se llevó a cabo mediante la consulta al comité de expertos y a otros expertos del sector, a través de la información facilitada en los cuestionarios y mediante debates con el comité de expertos.

\section{EL CONCEPTO DE ECONOMÍA SOCIAL Y LOS PRINCIPALES ENFOQUES TEÓRICOS CONEXOS}

\subsection{Identificación y reconocimiento de la economía social en la actualidad}

La definición más reciente del concepto de economía social, elaborada por sus propios miembros, se puede encontrar en la «Carta de Principios de la Economía Social» de Social Economy Europe, la asociación a escala europea que representa a la economía social. Estos principios son:

- primacía del objetivo individual y social frente al capital;

- adhesión voluntaria y abierta;

- control democrático por parte de los miembros (no afecta a las fundaciones, ya que estas no tienen miembros);

- combinación de los intereses de los miembros o los usuarios con el interés general;

- defensa y aplicación de los principios de solidaridad y de responsabilidad;

- gestión autónoma e independencia de las autoridades públicas;

- la mayoría de los excedentes se utilizan para conseguir objetivos de desarrollo sostenible, servicios de interés a los miembros o de interés general. 


\subsection{Una definición de economía social que se ajuste a los sistemas de contabilidad nacionales}

La definición propuesta, como ya se estableció en el informe de 2012, es la siguiente:

Conjunto de empresas privadas organizadas formalmente, con autonomía de decisión y libertad de adhesión, creadas para satisfacer las necesidades de sus socios a través del mercado, produciendo bienes y servicios, asegurando o financiando, y en las que la eventual distribución entre los socios de beneficios o excedentes así como la toma de decisiones no están ligadas directamente con el capital o cotizaciones aportados por cada socio, correspondiendo un voto a cada uno de ellos, o se llevan a cabo en todo caso mediante procesos democráticos y participativos de toma de decisiones. La economía social también agrupa a aquellas organizaciones privadas organizadas formalmente con autonomía de decisión y libertad de adhesión que producen servicios no de mercado a favor de las familias, cuyos excedentes, si los hubiera, no pueden apropiarse los agentes económicos que los crean, los controlan o los financian.

\section{Cuadro 1. Agentes de la economía social por sector institucional SEC 2010}

\begin{tabular}{|c|c|c|}
\hline \multicolumn{2}{|c|}{ SECTOR INSTITUCIONAL SEC 2010} & $\begin{array}{l}\text { EMPRESAS DE LA ECONOMÍA SOCIAL Y } \\
\text { ORGANIZACIONES MICROECONÓMICAS }\end{array}$ \\
\hline \multirow{3}{*}{ 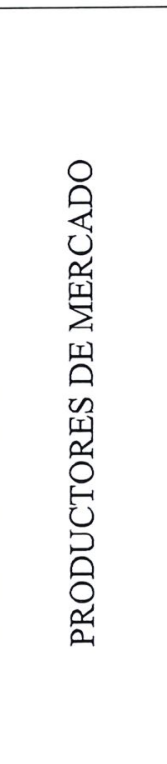 } & Sociedades no financieras (S11) & 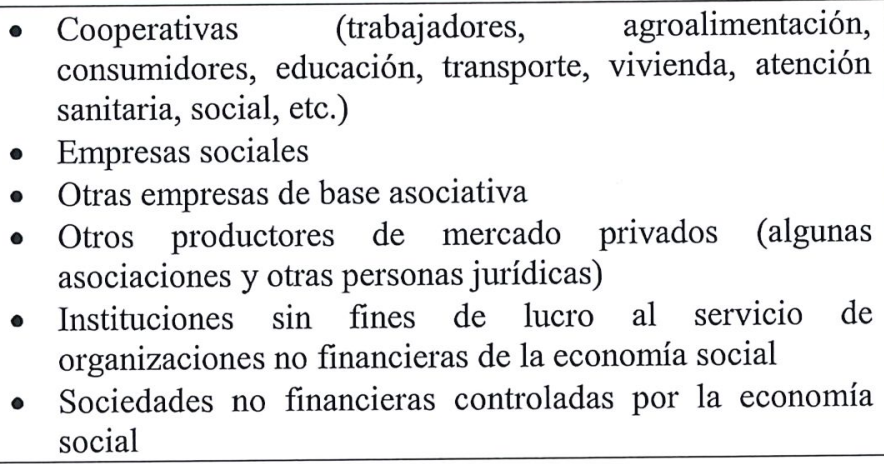 \\
\hline & Sociedades financieras (S12) & $\begin{array}{l}\text { - Cooperativas de crédito } \\
\text { - Mutualidades de seguros* y mutualidades de previsión } \\
\text { - Cooperativas de seguros } \\
\text { - Instituciones sin fines de lucro al servicio de } \\
\text { organizaciones no financieras de la economía social }\end{array}$ \\
\hline & Administraciones públicas (S13) & \\
\hline \multirow{2}{*}{ 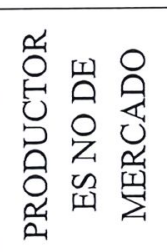 } & Hogares $(\mathrm{S} 14) * *$ & $\begin{array}{l}\text { - Instituciones sin fines de lucro al servicio de los hogares } \\
\text { sin gran importancia }\end{array}$ \\
\hline & $\begin{array}{l}\text { Instituciones sin fines de lucro al } \\
\text { servicio de los hogares (S15) }\end{array}$ & $\begin{array}{l}\text { - Asociaciones de acción social*** } \\
\text { - Fundaciones de acción social*** } \\
\text { - Otras organizaciones sin fines de lucro al servicio de los } \\
\text { hogares (culturales, deportivas, etc.) }\end{array}$ \\
\hline
\end{tabular}

(*) Excluidas las organizaciones de gestión del sistema de la seguridad social y, en general, las mutualidades de adhesión obligatoria y aquellas controladas por empresas no pertenecientes a la economía social.

(**) El sector de los Hogares (S14) incluye emprendedores individuales y asociaciones generales sin personalidad jurídica que son productores de mercado no pertenecientes a la economía social. También incluye organizaciones sin fines de lucro de tamaño limitado («sin gran importancia») que son productores no de mercado y forman parte de la economía social. 
(***) Organizaciones sin fines de lucro que son productores no de mercado privados, de adhesión y participación voluntarias y autonomía estratégica y operativa y cuya finalidad es la consecución de objetivos de bienestar social mediante la prestación o suministro de bienes y servicios sociales o preferentes, de manera gratuita o a precios no significativos desde un punto de vista económico, para personas o grupos de personas vulnerables, víctimas de exclusión social o en riesgo de exclusión. Estas organizaciones conforman el tercer sector de acción social que, obviamente, forma parte de la economía social.

\subsection{Principales enfoques teóricos relacionados con la economía social}

\section{El concepto de organización no lucrativa (ONL)}

El concepto moderno de sector no lucrativo fue definido con mayor precisión y difundido ampliamente en todo el mundo por un proyecto de investigación internacional que comenzó a principios de la década de 1990, dirigido por la Universidad Johns Hopkins (Baltimore, Estados Unidos), con el fin de descubrir y cuantificar su tamaño y estructura, analizar sus perspectivas de desarrollo y evaluar su repercusión en la sociedad.

Las organizaciones que examina este proyecto son aquellas que cumplen los cinco criterios fundamentales recogidos en la «definición estructural operativa» de las organizaciones sin fines de lucro, que son:

a) Organizaciones, es decir, poseen una estructura y presencia institucional. Por lo general son personas jurídicas;

b) Privadas, es decir, están institucionalmente separadas de los poderes públicos, aunque pueden recibir financiación pública e incluir en sus órganos directivos a funcionarios públicos;

c) Autónomas, es decir, con capacidad de control sobre sus actividades y libertad para elegir y cesar a sus órganos de gobierno;

d) No reparten beneficios, es decir, las organizaciones sin fines de lucro pueden generar beneficios pero deben ser reinvertidos en la misión principal de la organización y no distribuidos entre sus propietarios, miembros fundadores u órganos directivos;

e) Voluntarias, lo que significa dos cosas: en primer lugar, que la pertenencia a ellas no es obligatoria ni está legalmente impuesta y, en segundo lugar, que deben contar con la participación de voluntarios en sus actividades u órganos de gestión.

\section{El enfoque de la economía solidaria}

El concepto de «economía solidaria» se ha desarrollado en Francia desde la década de 1980. Con arreglo este enfoque, la economía gira en torno a tres polos: el mercado, el Estado y la reciprocidad. Estos tres polos corresponden a los principios de mercado, redistribución y reciprocidad. El último se refiere a un intercambio no monetario en el ámbito de la sociabilidad primaria que se identifica sobre todo con el asociacionismo. 
En resumen, la economía es plural por naturaleza y no puede reducirse a unos términos estrictamente comerciales y monetarios. El enfoque de la economía solidaria representa un intento sin precedentes de unir los tres polos del sistema, de forma que las iniciativas de la economía solidaria constituyen un híbrido entre las economías de mercado, de no mercado y no monetarias. No encajan en el estereotipo de mercado de economía ortodoxa y sus recursos también tienen distintos orígenes: de mercado (venta de bienes y servicios), de no mercado (subvenciones del gobierno y donaciones) y no monetarios (voluntariado).

Además de este concepto de economía solidaria, que tiene su epicentro en Francia, existe otra visión de la economía solidaria con cierta presencia en algunos países de América Latina que la considera una fuerza de cambio social, portadora de un proyecto de sociedad alternativa a la globalización neoliberal. A diferencia del enfoque europeo, que considera que la economía solidaria es compatible con el mercado y el Estado, la perspectiva latinoamericana se centra en el desarrollo de este concepto como alternativa mundial al capitalismo.

\section{Otros enfoques}

En relación con el enfoque descrito anteriormente, existen otros enfoques teóricos que proponen directamente sustituir las economías de mercado, en las que los medios de producción son privados, por otras formas de organización del sistema de producción. Entre ellas se incluyen a) la economía alternativa, que tiene su origen en los movimientos contestatarios que se desarrollaron en Francia después de mayo de 1968, y b) la economía popular, promovida en varios países de América Latina desde 1980, con características muy similares a la versión latinoamericana de la economía solidaria, hasta el punto que se conoce también como economía popular solidaria. La economía popular excluye todo tipo de relación empleador-empleado y considera el trabajo como principal factor de producción.

\section{LA ECONOMÍA SOCIAL Y LOS CONCEPTOS EMERGENTES RELACIONADOS EN EUROPA}

\subsection{Empresas sociales, emprendimiento social e innovación social}

La Comisión Europea define a las empresas sociales como parte integral de la economía social: "Una empresa social, agente de la economía social, es una empresa cuyo principal objetivo es tener una incidencia social, más que generar beneficios para sus propietarios o sus socios. Funciona en el mercado proporcionando bienes y servicios de manera empresarial e innovadora y utiliza sus excedentes principalmente para fines sociales. Está sometida a una gestión responsable y transparente, en concreto mediante la asociación de sus empleados, sus clientes y las partes interesadas de que se trate en su actividad económica» (Comunicación de la Comisión, de 25.10.2011, «Iniciativa en favor del emprendimiento social», COM/2011/0682 final). Esta Comunicación de la Comisión también identifica los principales ámbitos de actividad de las empresas sociales: a) empresas que proporcionan bienes o servicios sociales a personas vulnerables y b) empresas que persiguen la integración laboral de personas con dificultades para su empleabilidad, pero cuya actividad puede quedar al margen del ámbito de la prestación de bienes o servicios sociales. 
Por su parte, las distintas corrientes norteamericanas en relación con las empresas sociales se pueden agrupar en dos enfoques principales: «rentas del trabajo» y la escuela de la «innovación social», promovida por la Fundación Ashoka, creada por Bill Drayton en 1980.

El enfoque de la innovación social hace hincapié en el papel individual del emprendedor social, que adopta la misión de crear y sostener valores sociales (no solo el valor privado), reconoce y persigue nuevas oportunidades al servicio de esta misión, se embarca en un proceso de innovación, adaptación y aprendizaje continuos, actúa de manera valiente sin verse limitado por los recursos con los que cuenta y exhibe un sentido destacado de responsabilidad y rendición de cuentas respecto de las comunidades a las que sirve y los resultados creados. En resumen, los emprendedores sociales llevan a cabo una misión social y el impacto relacionado con dicha misión - más que la creación de riqueza - constituye el principal criterio que impulsa a un emprendedor social. En el enfoque de la innovación social, la forma de propiedad de la empresa social (pública, de capital o de economía social) es secundaria y la principal figura es el emprendedor social, principal persona responsable del emprendimiento y del cambio social. 


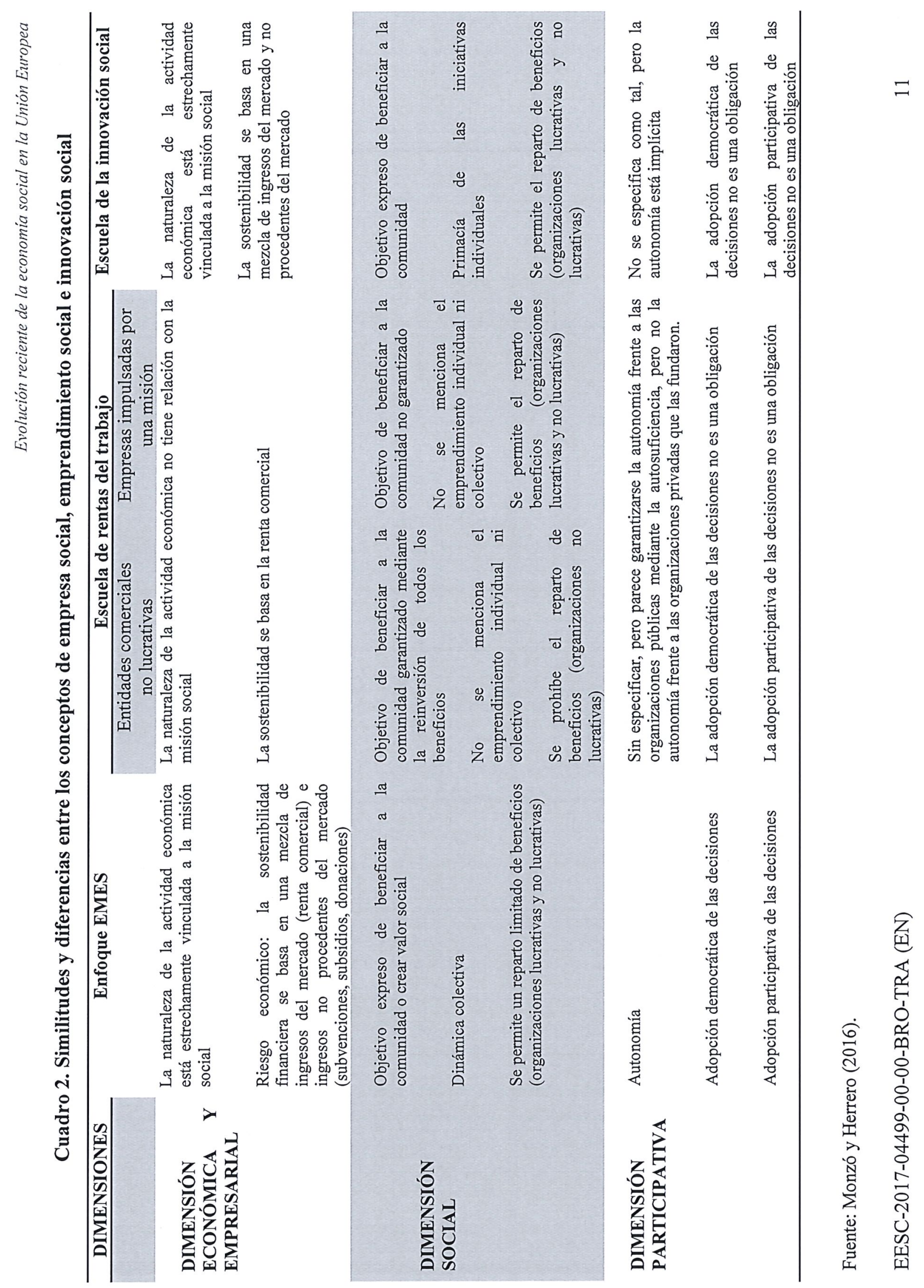




\subsection{La economía colaborativa, los conceptos conexos y la economía social}

Un nuevo concepto que se ha establecido con firmeza desde el comienzo del siglo XXI es el de la «economía colaborativa», que hace referencia a una amplia gama de actividades relacionadas con los ámbitos del consumo, la producción, la economía, la educación e incluso la gobernanza. En su Comunicación «Una Agenda Europea para la economía colaborativa» (COM/2016/0356 final, de 2.6.2016), la Comisión Europea define la economía colaborativa como «modelos de negocio en los que se facilitan actividades mediante plataformas colaborativas que crean un mercado abierto para el uso temporal de mercancías o servicios ofrecidos a menudo por particulares». La Comunicación define tres categorías de agentes implicados en la economía colaborativa: a) prestadores de servicios - particulares o profesionales-, b) usuarios de dichos servicios y c) intermediarios que - a través de una plataforma en línea - conectan a los prestadores con los usuarios y facilitan las transacciones entre ellos («plataformas colaborativas»). La Comunicación indica finalmente que las transacciones de la economía colaborativa no implican un cambio de propiedad y pueden realizarse con o sin ánimo de lucro.

Si bien no son cruciales para el boom actual de la economía colaborativa, las «plataformas colaborativas» están desempeñando un importante papel. Sus principales funciones son: a) la creación de una plataforma que conecte la oferta y demanda de bienes, b) la creación del mecanismo que permita la realización electrónica de las transacciones económicas, y c) la creación de mecanismos de verificación que minimicen los riesgos de las transacciones y los costes asociados a los tratos con desconocidos. En resumen, la economía colaborativa utiliza tecnologías de la información para reducir las asimetrías de la información y los costes de las transacciones de los bienes y servicios que se intercambian o comparten, y para ampliar y profundizar los mercados colaborativos.

En Europa también se están desarrollando varias plataformas colaborativas. LAMA y Cooperatives Europe llevaron a cabo un estudio de 38 casos de once países europeos y de tres iniciativas de fuera de la Unión Europea. En sus conclusiones, el estudio apuntaba a las nuevas oportunidades de expansión que ofrecían las cooperativas en el ámbito de la economía colaborativa y a los obstáculos y barreras a las que se enfrentan, que incluyen los problemas de financiación y el pequeño tamaño de las cooperativas que promueven iniciativas de economía colaborativa, lo que provoca que pierdan parte de su eficiencia.

\subsection{La economía del bien común y la economía social}

La economía del bien común (EBC) (1) es un movimiento socioeconómico y político fundado por el economista austríaco Christian Felber en 2010. La proposición central del modelo de la EBC es que la economía debe estar al servicio de las personas, esto es, del bien común. La EBC está fundamentada en los valores que todas las personas reconocen como universales: la dignidad humana, la solidaridad, la sostenibilidad ecológica, la justicia social, la transparencia y la participación democrática. El modelo de la EBC es interdisciplinar y se puede aplicar a todo tipo de empresas y organizaciones. 
Para reconocer la contribución al bien común de las empresas y entidades que conforman el sistema económico se utiliza un método específico basado en el Balance del Bien Común (BBC), la Matriz del Bien Común (MBC), el Informe del Bien Común y la Auditoría Externa del Bien Común.

\subsection{La economía circular y la economía social}

El modelo de economía circular consiste en sustituir una economía lineal, basada en el modelo «se coge, se fabrica, se usa y se elimina», por una economía circular en la que los residuos se puedan transformar en recursos, para que la economía sea más sostenible y reducir así su impacto ambiental negativo por medio de una mejor gestión de los recursos y una reducción de la extracción y de la contaminación. Al mismo tiempo, la economía circular permite a las empresas lograr ventajas competitivas gracias a una mejor gestión de las materias primas, ofreciendo nuevas oportunidades económicas en nuevos mercados y permitiendo la creación de nuevos puestos de trabajo a escala local.

La economía circular y la economía social tienen numerosos puntos en común. Ambos modelos colocan a las personas y al desarrollo sostenible en el centro de sus preocupaciones. En la economía circular, al igual que en la economía social, un factor clave de su éxito es el refuerzo de la capacidad creativa e innovadora a escala local, donde las relaciones de proximidad constituyen un elemento decisivo. En otras palabras, los valores y principios del movimiento cooperativo y de la economía social, como los vínculos con el entorno local, la intercooperación o la solidaridad, son pilares decisivos para garantizar los procesos de desarrollo sostenible en su triple dimensión: medioambiental, económica y social. No es casual que en Europa la economía social fuera pionera de la economía circular a la hora de reutilizar y reciclar los residuos, en el ámbito de la energía y la agricultura. Más recientemente, las plataformas cooperativas en el ámbito de la economía colaborativa constituyen ejemplos bien conocidos de iniciativas que ayudan a preservar y mejorar el capital natural, a optimizar el uso de los recursos y a promover la eficiencia del sistema. La propia Comisión Europea, en su documento «Un plan de acción de la UE para la economía circular», reconocía que las empresas de la economía social contribuirían de manera clave a la economía circular.

\subsection{Responsabilidad social de las empresas, ciudadanía corporativa y economía social}

En 2011, la Comisión Europea publicó su Libro Verde titulado «Fomentar un marco europeo para la responsabilidad social de las empresas», y definía la responsabilidad social de las empresas como «la integración voluntaria, por parte de las empresas, de las preocupaciones sociales y medioambientales en sus operaciones comerciales y sus relaciones con sus interlocutores»».

Un concepto vinculado estrechamente a la responsabilidad social de las empresas es el de ciudadanía corporativa. Las teorías sobre la ciudadanía corporativa sugieren que una empresa no solo debería asumir responsabilidades con respecto a sus accionistas y partes interesadas, sino que la propia 
empresa debería implicarse en la sociedad. La empresa debe actuar como un «buen ciudadano». Si bien la definición inicial de responsabilidad social de las empresas se restringía a las buenas prácticas de una empresa directamente relacionadas con sus accionistas y partes interesadas, la nueva definición de la Comisión Europea se identifica literalmente con los diez principios del Pacto Mundial de las Naciones Unidas (COM(2006)136 final, punto 2), por lo que se puede extraer la conclusión de que los dos conceptos son equivalentes, al menos en el programa de la Comisión.

Dado que los principios de la economía social, inspirados por los principios cooperativos, no son más que la aplicación de la responsabilidad social de las empresas en todos sus aspectos, se puede afirmar que la economía social ha sido la pionera en la aplicación de la responsabilidad social de las empresas, dado que esta forma parte integral de los valores y normas operativas de la economía social.

\subsection{Reconocimiento nacional del concepto de economía social y conceptos emergentes relacionados}

- Países en los que el concepto de economía social está ampliamente reconocido: en España, Francia, Portugal, Bélgica y Luxemburgo, el concepto de economía social disfruta del máximo reconocimiento por parte de los entes públicos y del mundo académico y científico, así como del propio sector de la economía social. Destacan los dos primeros países, ya que Francia es el lugar de nacimiento de este concepto, y España aprobó la primera ley nacional europea sobre la economía social en 2011.

- Países en los que el concepto de economía social disfruta de un nivel moderado de reconocimiento: Italia, Chipre, Dinamarca, Finlandia, Suecia, Letonia, Malta, Polonia, el Reino Unido, Bulgaria, Grecia, Hungría, Irlanda, Rumanía y Eslovenia. En estos países, el concepto de economía social coexiste con otros conceptos, como el sector no lucrativo, el sector del voluntariado y las empresas sociales. En el Reino Unido, el bajo nivel de concienciación sobre la economía social contrasta con la política gubernamental de apoyo a las empresas sociales.

- Países en los que el concepto de economía social tiene poco o ningún reconocimiento: el concepto de economía social es poco conocido, relativamente nuevo o desconocido en Austria, la República Checa, Estonia, Alemania, Letonia, Lituania, Malta, los Países Bajos, Eslovaquia y Croacia. Los términos conexos de sector no lucrativo, sector del voluntariado y sector de las organizaciones no gubernamentales tienen un nivel relativamente mayor de reconocimiento.

En lo que respecta a los conceptos emergentes conexos, los más conocidos en los países de la UE son «no lucrativo», «tercer sector», «sector de la sociedad civil y el voluntariado», «responsabilidad social de las empresas», «empresas sociales» e «innovación social». Otros conceptos como «economía circular»o «economía colaborativa» muestran una tendencia al alza en los niveles de conocimiento en la mayoría de los países de la UE, mientras que los conceptos de «economía del bien común» y «economía solidaria» lo tienen difícil para abrirse paso en algunos países de la UE, donde son poco o nada conocidos. 


\section{POLÍTICAS PÚBLICAS PARA LA ECONOMÍA SOCIAL A ESCALA EUROPEA EN LOS ÚLTIMOS AÑOS (2010-2016)}

\subsection{Normas: estatutos y marcos reglamentarios}

Entre 2009 y 2017, las instituciones europeas han implantado varias iniciativas en relación con la economía social o, más exactamente, para las empresas sociales que forman parte de la economía social, abriendo así un nuevo período de políticas públicas europeas. En lo que respecta a las formas jurídicas, se han producido pocos avances. Los proyectos de Estatuto europeo para las mutualidades y de Estatuto de la Fundación Europea fueron objeto de debate pero finalmente fueron retirados, debido a la falta de apoyo institucional. En la actualidad, el Parlamento Europeo ha tomado la iniciativa legislativa para trabajar sobre un estatuto para las empresas sociales y solidarias.

En lo que respecta a los marcos reglamentarios y a los obstáculos jurídicos al desarrollo de entidades de la economía social, las Directivas aprobadas no habían prestado hasta hace poco la atención suficiente a las características específicas de las organizaciones de la economía social. La prioridad era la aplicación de la política de competencia. Más recientemente, para mitigar este marco reglamentario, la Comisión aprobó en 2012 el Reglamento sobre las ayudas de minimis a las empresas que prestan servicios de interés económico general, y en 2014 se aprobó el paquete de reforma de la contratación pública. Este permite a las autoridades públicas incluir determinadas cláusulas sociales en los procedimientos y en los mandatos de contratación pública. No obstante, ha tenido pocas repercusiones. En el contexto del marco reglamentario, uno de los nuevos obstáculos que ha ido desarrollándose es una política de austeridad cualitativa. Tiene que ver con el modo en que las entidades del sector público y de la economía social se relacionan entre sí, no solo con respecto al problema de la mayor burocracia, sino también a los retrasos, los procedimientos de aplicación e implantación y otros requisitos que complican, o incluso impiden, la colaboración entre el tercer sector y el sector público.

Se han acometido esfuerzos en las administraciones europeas y nacionales para mejorar la dimensión cognitiva y la participación por parte de la sociedad civil, como las conferencias europeas organizadas por las Presidencias del Consejo de la Unión Europea o en el marco de una Presidencia, los sucesivos dictámenes del CESE, las iniciativas y las opiniones del Intergrupo sobre Economía Social del Parlamento Europeo y, en algunos casos, los del Comité de las Regiones, o incluso los de la propia Comisión. La última iniciativa, adoptada en Madrid (23 de mayo de 2017), fue la adopción de la «Declaración de Madrid», que logró un gran impacto en los medios de comunicación y en las redes sociales. No obstante, para que aumente la visibilidad y la receptividad sociales, es necesario el paso de un entorno a gran escala a uno a pequeña escala. Además, de este modo, el tejido social de las sociedades, su capital social de redes, se convierte en un factor clave. Tal y como han constatado informes anteriores, los programas europeos en virtud del Fondo Social Europeo han logrado un amplio efecto de estructuración, tanto a nivel nacional como internacional, a la hora de reunir y 
reforzar la economía social europea en términos de federaciones, redes, investigación, cultura y políticas. Por otra parte, los fondos y programas de la UE deben hacer frente a considerables dificultades para que las redes locales puedan acceder a ellos.

Tal y como se ha mencionado anteriormente, otro problema es la admisibilidad y el reconocimiento de la definición del concepto de ámbito de la economía social. El despliegue periódico de «neoconceptos» tampoco ayuda. En la década de 1970, la multitud de términos relacionados con la economía social incluía al tercer sector, a la sociedad civil y a las entidades no lucrativas. En el contexto de la crisis económica, ha surgido una nueva ola de conceptos, como empresas sociales, economía colaborativa y economía del bien común. Es preciso hacer hincapié en que estas cuestiones no solo enmascaran una falta de consenso sobre la designación que debe utilizarse, sino también una política oculta para no avanzar en este campo.

\subsection{Políticas específicas: fondos y ámbitos políticos}

Un importante cambio en el programa político de la Comisión Europea en relación con la economía social —o, de manera más precisa, las empresas sociales — se produjo en 2011, cuando la Comisión comenzó a aplicar la Comunicación «Iniciativa en favor del emprendimiento social. Construir un ecosistema para promover las empresas sociales en el centro de la economía y la innovación sociales» (COM(2011)682 final). La Iniciativa en favor del emprendimiento social recogía el programa político de la Comisión Europea con once medidas clave. Uno de los ejes es mejorar la financiación pública y privada. Al objeto de aumentar el interés de los inversores privados en las empresas sociales, se aprobó el Reglamento (UE) n. ${ }^{\circ}$ 346/2013 sobre los fondos de emprendimiento social europeos (EuSEF). También se creó el Programa de la Unión Europea para el Empleo y la Innovación Social (EaSI) en colaboración con otras iniciativas financieras, como el Instrumento Financiero de Garantía EaSI, el Mecanismo de inversión de creación de capacidades EaSI y el Acelerador de Impacto Social (AIS). En lo que respecta a los fondos públicos, el objetivo de «promoción de la economía social y el emprendimiento social» se transfirió desde el FEDER al FSE. Sin embargo, aún no se ha puesto en marcha, y se espera, una política presupuestaria europea específicamente destinada a la economía social. La reciente Declaración de Madrid, de 23 de mayo de 2017, sigue reclamándola.

Nuestro estudio con los corresponsales ha revelado la importancia del principal instrumento financiero de la UE, el FSE. Los congresos y las redes internacionales, la iniciativa LEADER y la legislación y las directivas europeas también han demostrado ser medidas clave. Los congresos y las redes se han revelado como una herramienta para generar efectos de estructuración y conocimiento, como coordinar la sociedad civil de la economía social europea. Las nuevas herramientas de reciente creación (FEIE, EaSI, COSME, etc.) han demostrado tener un impacto reducido o nulo, especialmente en los países mediterráneos y del este de la UE. Es necesario elaborar estudios para evaluar el impacto de las nuevas políticas. 


\section{POLÍTICAS PÚBLICAS PARA LA ECONOMÍA SOCIAL A ESCALA NACIONAL Y REGIONAL EN EUROPA EN LOS ÚLTIMOS AÑOS (2010-2016)}

\subsection{Nuevas medidas legislativas nacionales sobre la economía social}

Durante los últimos siete años, la mayoría de los países europeos han prestado atención a la elaboración de legislación relacionada con la economía social. Se han aprobado leyes específicas sobre la economía social a escala nacional en España (2011), Grecia (2011 y 2016), Portugal (2013), Francia (2014) y Rumanía (2016), y a nivel regional en Bélgica (Valonia, Bruselas y Flandes) y España (Galicia).

Además, en este período han surgido nuevos proyectos de ley, borradores y otras iniciativas institucionales, como sistemas de acreditación, etiquetas y grandes planes plurianuales nacionales, que revelan un interés creciente de las administraciones públicas en este ámbito. También se han aprobado reformas para grupos específicos de la economía social (tercer sector social, empresas sociales del tercer sector, cooperativas y otras), por ejemplo, en Italia y en España.

La regulación de la economía social mediante nuevas formas jurídicas no constituye como tal un avance para promover la economía social que vaya más allá del reconocimiento institucional (Noia, 2017). Al igual que sucedía hasta hace poco con el Estatuto de la Sociedad Cooperativa Europea o la Ley española de Economía Social, los efectos podían ser demasiado limitados si la ley no iba acompañada de otras medidas.

\subsection{Planes de acción nacionales y regionales y financiación específica}

Los planes de acción nacionales y regionales son políticas clave para impulsar la economía social. Constituyen acuerdos importantes entre distintos agentes, principalmente entre la administración pública y representantes de la economía social o del tercer sector, pero también comprenden sindicatos, universidades y otros, con el objetivo de mejorar su relación mutua en aras de las ventajas para todos a largo plazo. Incluyen marcos de financiación por lo general estables, regímenes participativos y consultivos, ámbitos estratégicos de desarrollo y mejoras en las relaciones y el cambio social.

A escala regional y local, en la última década se han desarrollado buenas prácticas en las regiones de Andalucía y Murcia (sur de España), que han alcanzado los niveles más elevados de desarrollo de cooperativas del país, y en varias regiones de Francia y Bélgica (Chaves y Demoustier, 2013). Durante esta década, se han podido encontrar otros ejemplos de buenas prácticas en Francia, como el Polo territorial de cooperación económica (PTCE), reconocido por la nueva Ley francesa sobre la 
economía social, o los planes locales para promover las empresas sociales y solidarias, como en Barcelona (España).

A escala nacional, y normalmente en cooperación con los fondos estructurales europeos, se han establecido varios planes de acción nacionales en los últimos años. Se trata de casos en los que los programas operativos de los fondos europeos se destinan a la economía social y a la inclusión social. En el cuadro 3 se recogen los principales planes nacionales. Hay tres factores clave para el éxito que son importantes: en primer lugar, un marco plurianual y global; en segundo lugar, el concepto de asociación entre la administración pública, la economía social y otras partes interesadas, que garantice que se satisfacen las necesidades y prioridades reales; y, por último, el efecto de estructuración e inclusión de los fondos estructurales europeos en toda Europa. Este último constituye una lección esencial para los legisladores de la UE.

Cuadro 3 - Planes nacionales que impulsan la economía social en países europeos (2011-2016)

\begin{tabular}{|l|l|}
\hline \multicolumn{1}{|c|}{ País } & \multicolumn{1}{c|}{ Plan nacional } \\
\hline Bulgaria & Plan de acción para la economía social (2014-2015, 2016-2017) \\
\hline Polonia & $\begin{array}{l}\text { Programa nacional para la economía social. Establecimiento del Comité } \\
\text { nacional para el desarrollo de la economía social }\end{array}$ \\
\hline Portugal & $\begin{array}{l}\text { Acuerdo nacional entre el gobierno y el sector social («Compromissos de } \\
\text { Cooperação para o Setor Social e Solidário») }\end{array}$ \\
\hline Rumanía & $\begin{array}{l}\text { Solidar - Apoyo para la consolidación del programa de la economía social, } \\
\text { en virtud del Programa operativo de capital humano (POCU) }\end{array}$ \\
\hline España & $\begin{array}{l}\text { Programa de Fomento e Impulso de la Economía Social y Programa } \\
\text { Operativo de Inclusión Social y Economía Social (POISES), FSE, 2014- } \\
\text { 2020. }\end{array}$ \\
\hline Suecia & $\begin{array}{l}\text { Programa plurianual de apoyo a las empresas sociales de integración } \\
\text { laboral, del Departamento de Trabajo y del Departamento de Empresa. }\end{array}$ \\
\hline Reino Unido & $\begin{array}{l}\text { El Pacto, un acuerdo entre la administración pública y el sector comunitario } \\
\text { y del voluntariado. Creado en 1998, establece un modo de trabajar que } \\
\text { mejora su relación para lograr ventajas mutuas. }\end{array}$ \\
\hline
\end{tabular}

Financiación específica. Existen varios marcos de financiación en toda Europa. Algunos entrañan principalmente fondos públicos, otros fondos privados y otros constituyen sistemas híbridos de financiación pública y privada. En el presente documento nos centraremos en la financiación específica basada en reglamentos o fondos públicos.

Los fondos públicos destinados a la economía social constituyen el primer pilar de financiación. La UE (por ejemplo, con sus fondos estructurales) y las administraciones nacionales y regionales asignan fondos expresamente para la promoción y desarrollo de la economía social. Se trata de programas tradicionales de subvención para la promoción de cooperativas y del empleo en cooperativas, en Alemania, Italia y Lspaña. Se pucden implantar numerosas alternativas. 
En los últimos años, varios gobiernos en toda Europa han desplegado este tipo de fondos. En Bélgica, el fondo Brasero apoya el desarrollo de las cooperativas de trabajadores en la región de Valonia. En Chipre, la política de los Servicios de Bienestar Social ofrece subvenciones anuales para los gastos corrientes, financiando a organizaciones que prestan servicios de bienestar (guarderías, prestaciones de dependencia, etc.). En Francia, la nueva Ley sobre la economía social ha establecido nuevos instrumentos financieros para el sector, como un fondo de innovación social (FISO). En Italia se ha creado un fondo para financiar empresas sociales y cooperativas sociales.

En algunos casos se trata de fondos mixtos, gestionados por la administración y por organizaciones de la economía social: algunos ejemplos en Francia son el Fondo Nacional para el Desarrollo de la Vida Asociativa (FNDVA) y el Fondo Nacional para el Desarrollo del Deporte (FNDS). En varios fondos, la financiación se ofrece al margen del presupuesto. Otros sistemas se basan en un impuesto personal sobre la renta. Los ciudadanos pueden asignar un porcentaje del impuesto a pagar a organizaciones de voluntariado. Así sucede en Italia y España. En España, estas sumas se abonan a un fondo nacional para las organizaciones del tercer sector social, que recibe más de 200 millones de euros anuales.

Otro recurso específico tradicional se obtiene de los ingresos que producen los juegos de azar (loterías, máquinas tragaperras). Este es el caso de RAY y Oy Veikkaus AB, en Finlandia, y de la ONCE (Organización Nacional de Ciegos Españoles), en España.

\subsection{Normas de contratación pública}

Tras un largo período en el que la protección de la competencia era la política dominante en los mercados públicos, la revisión en 2014 de la normativa de la UE en materia de contratación pública (Directivas 2014/23/UE, 2014/24/UE y 2014/25/UE) abrió nuevas oportunidades para que las administraciones nacionales, regionales y locales promovieran la economía social, al facilitar su acceso a la condición de proveedores del sector público. Se trata, por tanto, de una política en el lado de la demanda para impulsar la economía social. Ahora es posible incluir cláusulas sociales en los procedimientos para la adjudicación de contratos públicos.

Numerosas administraciones a escala nacional, regional y local han aplicado estas cláusulas sociales, como en Suecia, España y el Reino Unido. En el Reino Unido, la Ley de valor social (servicios públicos) de 2012 exige a los organismos públicos que contraten servicios públicos que tengan en cuenta el modo en que dichos servicios acarrearían mejoras económicas y sociales en la zona donde se prestarán. En España, ciudades como Zaragoza, Barcelona y Madrid han introducido recientemente cláusulas sociales en sus nuevos contratos públicos. 


\subsection{Obstáculos institucionales}

En el presente informe también hemos abordado lo que entienden los profesionales y los representantes de la economía social por principales obstáculos al desarrollo de este sector, centrándonos en los obstáculos institucionales. De hecho, este es un modo de medir la eficacia de las políticas aplicadas o que aún no se hayan introducido. La pregunta incluida en el cuestionario era muy abierta, se han recibido distintas respuestas. Identifican cuatro grupos de obstáculos: la visibilidad y la concienciación, el liderazgo y la administración, la financiación y la fiscalidad y los obstáculos institucionales.

El primer grupo de obstáculos tiene que ver con la falta de concienciación y comprensión, en la sociedad, en el debate público y en el sector académico, del concepto de economía social, empresas sociales y otros conceptos conexos. Este es un obstáculo muy importante para los países del este de la UE, como Hungría, Polonia, Eslovaquia o la República Checa. Los corresponsales en estos países reconocen que el principal apoyo para la economía social - financiero y de concienciaciónproviene de los programas e iniciativas de la UE.

Vinculada a esta falta de concienciación y comprensión está la baja visibilidad de la economía social, en los medios de comunicación y también en las estadísticas. La ausencia de bases de datos, estadísticas oficiales e información fiable sobre las empresas sociales o la economía social se dan en muchos países, desde Austria y Eslovaquia hasta Suecia. Además, se requieren programas educativos y de formación en el ámbito de la economía social en todos los niveles de la enseñanza. En algunos países, como Francia, existen programas como la formación a través de cooperativas para adolescentes o jóvenes estudiantes.

Un segundo grupo de obstáculos tiene que ver con el liderazgo y la administración pública. Numerosos corresponsales afirman que faltan instituciones líderes con responsabilidad en materia de economía social, empresas sociales, voluntariado y sociedad civil que puedan desarrollar políticas e impulsar la economía social. En consecuencia, no existe una estrategia nacional para la economía social. Este ámbito no se considera una prioridad política. Los corresponsales de países como Alemania y Malta consideran que la mayoría de los medios de comunicación y responsables políticos «no ven la necesidad» de una economía social. En algunos casos, observan falta de confianza y rechazo a las actividades económicas llevadas a cabo por las organizaciones no lucrativas.

En parte como consecuencia de lo anterior, los órganos públicos no son los adecuados para atender a las necesidades y los esfuerzos de la economía social. En algunos casos, la administración multinivel y los distintos ministerios no están coordinados en materia de economía social. En otros casos, los órganos de la administración dependen en gran medida de los ciclos políticos; por ejemplo, en 2015, la oficina gubernamental danesa para las empresas de la economía social fue cerrada cuando se produjo un cambio de gobierno. Por último, pero no menos importante, la burocracia y las políticas de austeridad cualitativa (Chaves y Zimmer, 2017) son obstáculos muy importantes a las entidades de la economía social que trabajan con los entes públicos, por ejemplo, en Italia, España y Eslovenia. 
Otro grupo de obstáculos son los obstáculos institucionales. Se han tomado en consideración dos tipos. El primero son los cambios en la normativa del sector, que constituye un obstáculo al funcionamiento de las entidades de la economía social. En Francia y en España, los cambios gubernamentales en la normativa complementaria de protección social han afectado negativamente a las mutualidades de salud en los últimos años, llegando en algunos casos a obligarlas a cambiar su estatuto jurídico por el de entidades no lucrativas. En Italia, la reforma de las bancas populares (DL 3/2015) establece que aquellas entidades con activos superiores a los 8000 millones de euros deben transformarse en sociedades anónimas. Además, la reforma de las cooperativas de crédito (L 49/2016) reorganizó de manera radical la totalidad del sector de la banca cooperativa, con algunos aspectos negativos. En España, los cambios en el tratamiento por parte de la seguridad social de los entrenadores deportivos han perjudicado a las asociaciones deportivas. En el Reino Unido, los grandes contratos públicos relegan a las entidades de la economía social a la subcontratación para grandes empresas del sector privado; además, la tendencia, a pesar de la Ley de valor social, es adjudicar los contratos en función del precio y no porque aporten valor social añadido. La reciente modificación del estatuto jurídico de las organizaciones benéficas se adapta mejor a este nuevo marco institucional. En Finlandia, la Directiva sobre contratación pública que permitía que los contratos se reservaran a determinados servicios no se está aplicando, por lo que no puede beneficiar a las entidades de la economía social.

E1 segundo tipo de obstáculo institucional tiene que ver con nuevas normas y estatutos para las empresas sociales. El primer obstáculo es la no aplicación de las nuevas normas (que, por tanto, se consideran normas no vinculantes). Este es el caso de la Ley española de Economía Social (2011), que no cuenta con reglamentos de aplicación.

El segundo obstáculo en este segundo tipo de obstáculo institucional tiene que ver con las nuevas dificultades que han surgido para otras entidades de la economía social debido a las nuevas formas jurídicas nacionales de economía social o a los cambios en las formas jurídicas. En Polonia y Portugal, los recientes cambios en las leyes sobre las cooperativas no se consideran adecuados para las cooperativas. En Hungría, la nueva ley de economía social plantea un riesgo para numerosas cooperativas sociales, creadas por grupos de ciudadanos, que podrían tener que transformarse en otro tipo de organizaciones (cooperativa o sociedad limitada no lucrativa) cuando la ley entre en vigor en 2018. En Eslovenia y Bulgaria, la ley de emprendimiento social excluye a distintas organizaciones que ya han estado trabajando como empresas sociales. 


\section{EL PESO DE LA ECONOMÍA SOCIAL EN LOS 28 ESTADOS MIEMBROS DE LA UE}

\subsection{Introducción: la necesidad de estadísticas sobre la economía social}

Durante las últimas dos décadas se han acometido esfuerzos, tanto en el ámbito académico como por parte de los institutos nacionales de estadística y las administraciones nacionales. En 2006, el CIRIEC elaboró un método para la Comisión Europea, el «Manual para la elaboración de las cuentas satélite de las empresas de la economía social», en paralelo con el Manual de las Naciones Unidas para las cuentas satélite de las organizaciones no lucrativas. También se han desarrollado otros métodos para la elaboración de estadísticas. Algunos países han dedicado gran cantidad de esfuerzo en los últimos años a ofrecer datos fiables sobre los distintos grupos de la economía social. Los institutos de estadística de Francia y el Ministerio de Empleo de España proporcionan series cronológicas sobre el empleo en las cooperativas y en la economía social. Italia, Bulgaria, Luxemburgo, la República Checa y Hungría han logrado importantes mejoras en las estadísticas que publican sus institutos nacionales de estadística, utilizando en algunos casos la metodología de cuentas satélite para las organizaciones no lucrativas. Es preciso hacer una mención especial a Portugal, Polonia y Rumanía. Estos tres países de la UE han desarrollado estadísticas periódicas y sistemáticas para el conjunto de la economía social en los últimos años. En Portugal, este es el mandato de la Ley portuguesa sobre la economía social (2013), y en Polonia es la consecuencia de un acuerdo con el Fondo Social Europeo (FSE). Pese a ello, es preciso redoblar los esfuerzos para sistematizar las estadísticas de los distintos grupos de la economía social en los próximos años.

\subsection{Finalidad y metodología: desafíos}

La finalidad de esta parte del estudio es ofrecer una síntesis de las principales cifras de la economía social en la Unión Europea, por países y en su conjunto, diferenciando tres grupos de organizaciones: cooperativas y tipos similares aceptados; mutualidades y tipos similares; y asociaciones, fundaciones y otros tipos no lucrativos conexos.

Es esencial elaborar estadísticas a partir de estudios de campo y cuentas verificables. No obstante, por motivos de coste y tiempo, ello supera el alcance del presente estudio y deberá abordarse en una etapa posterior. La información estadística que se facilita en el presente estudio ha sido elaborada a partir de datos secundarios facilitados por nuestros corresponsales en cada país. El período de referencia es 2014-2015. No obstante, por motivos de disponibilidad y de calidad de la comunicación de las estadísticas, la información correspondiente a algunos países data de varios años, en particular en el caso de las asociaciones, las fundaciones y otras organizaciones similares. Las cifras buscadas eran el número de personas empleadas $y$, si era posible, el equivalente a tiempo completo, el número de miembros, el número de voluntarios y el número de entidades o empresas. En el caso de algunos países y grupos de la economía social, los datos sobre la cifra de negocio también estaban disponibles, pero no eran comparables. A efectos de comparabilidad con los datos procedentes de estudios 
anteriores elaborados por el CIRIEC para el CESE sobre la situación de la economía social en la Unión Europea de los Veinticinco en los períodos 2002/2003 y 2009/2010, se ha prestado especial atención a la variable «empleo».

\subsection{Síntesis de los resultados estadísticos}

Los siguientes totales subrayan el hecho de que la economía social europea es muy importante, tanto en términos humanos como económicos, y que constituye una realidad que debe ser tomada en consideración por la sociedad y por los responsables políticos.

La economía social europea proporciona:

- más de 13,6 millones de empleos remunerados en Europa;

- el equivalente a cerca del 6,3 \% de la población activa de la Europa de los Veintiocho;

- empleo de una mano de obra superior a los 19,1 millones, incluido el empleo remunerado y no remunerado;

- más de 82,8 millones de voluntarios, el equivalente a 5,5 millones de trabajadores a tiempo completo;

- más de 232 millones de miembros de cooperativas, mutualidades y entidades similares;

- más de 2,8 millones de entidades y empresas.

El panorama es distinto en cada uno de los países de la UE. Si bien el empleo en la economía social supone entre un $9 \%$ y un $10 \%$ de la población activa de países como Bélgica, Italia, Luxemburgo, Francia y los Países Bajos, en los nuevos Estados miembros de la UE como Eslovenia, Rumanía, Malta, Lituania, Croacia, Chipre y Eslovaquia, la economía social sigue siendo un sector pequeño y emergente, que emplea a menos del $2 \%$ de la población activa.

Otra conclusión tiene que ver con la evolución de la mano de obra de la economía social durante la crisis económica. La mano de obra de la economía social se ha revelado resiliente a la crisis económica, ya que solo ha descendido desde el 6,5\% al 6,3\% del total de mano de obra remunerada europea, y de los 14,1 millones de puestos de trabajo a los 13,6 millones, que se explican en parte por la calidad de los datos estadísticos disponibles. La reducción de la mano de obra remunerada es mayor en las cooperativas y en entidades similares que en las asociaciones, las fundaciones y otras entidades similares.

Por último, si se mide en términos de empleo, ya que otras medidas de impacto económico, como la contribución al PIB, no están disponibles de manera inmediata, las asociaciones, las fundaciones y otras entidades similares siguen siendo la principal «familia» de la economía social, y comprenden la mayoría de las entidades o empresas sociales y alrededor del $66 \%$ del empleo en este sector social. 
Cuadro 4. Empleo remunerado en cooperativas, mutualidades, asociaciones, fundaciones y entidades similares. Unión Europea (2014-2015)

\begin{tabular}{|c|c|c|c|c|}
\hline País & $\begin{array}{c}\text { Cooperativas } \\
\text { y entidades } \\
\text { similares } \\
\end{array}$ & Mutualidades & $\begin{array}{c}\text { Asociaciones y } \\
\text { Fundaciones }\end{array}$ & Total \\
\hline Austria & 70474 & 1576 & 236000 & 308050 \\
\hline Bélgica & 23904 & 17211 & 362806 & 403921 \\
\hline Bulgaria & 53841 & 1169 & 27040 & 82050 \\
\hline Croacia & 2744 & 2123 & 10981 & 15848 \\
\hline Chipre & 3078 & $(\mathrm{n} / \mathrm{d})$ & 3906 & 6984 \\
\hline Chequia & 50310 & 5368 & 107243 & 162921 \\
\hline Dinamarca & 49552 & 4328 & 105081 & 158961 \\
\hline Estonia & 9850 & 186 & 28000 & 38036 \\
\hline Finlandia & 93511 & 6594 & 82000 & 182105 \\
\hline Francia & 308532 & 136723 & 1927557 & 2372812 \\
\hline Alemania & 860000 & 102119 & 1673861 & 2635980 \\
\hline Grecia & 14983 & 1533 & 101000 & 117516 \\
\hline Hungría & 85682 & 6948 & 142117 & 234747 \\
\hline Irlanda & 39935 & 455 & 54757 & 95147 \\
\hline Italia & 1267603 & 20531 & 635611 & 1923745 \\
\hline Letonia & 440 & 373 & 18528 & 19341 \\
\hline Lituania & 7000 & 332 & $(\mathrm{n} / \mathrm{d})$ & 7332 \\
\hline Luxemburgo & 2941 & 406 & 21998 & 25345 \\
\hline Malta & 768 & 209 & 1427 & 2404 \\
\hline Países Bajos & 126797 & 2860 & 669121 & 798778 \\
\hline Polonia & 235200 & 1900 & 128800 & 365900 \\
\hline Portugal & 24316 & 4896 & 186751 & 215963 \\
\hline Rumanía & 31573 & 5038 & 99774 & 136385 \\
\hline Eslovaquia & 23799 & 2212 & 25600 & 51611 \\
\hline Eslovenia & 3059 & 319 & 7332 & 10710 \\
\hline España & 528000 & 2360 & 828041 & 1358401 \\
\hline Suecia & 57516 & 13908 & 124408 & 195832 \\
\hline Reino Unido & 222785 & 65925 & 1406000 & 1694710 \\
\hline TOTAL EU-28 & 4198193 & 407602 & 9015740 & 13621535 \\
\hline
\end{tabular}


Cuadro 5. Empleo remunerado en la economía social en comparación con el total de empleo remunerado.

Unión Europea (2014-2015)

\begin{tabular}{|l|r|r|r|}
\hline \multicolumn{1}{|c|}{ País } & $\begin{array}{r}\text { Empleo en la } \\
\text { economía } \\
\text { social (A) }\end{array}$ & Empleo total * (B) & $\begin{array}{c}\text { \% } \\
\text { A B }\end{array}$ \\
\hline Austria & 308050 & 4068000 & $7,6 \%$ \\
\hline Bélgica & 403921 & 4499000 & $9,0 \%$ \\
\hline Bulgaria & 82050 & 2974000 & $2,8 \%$ \\
\hline Croacia & 15848 & 1559000 & $1,0 \%$ \\
\hline Chipre & 6984 & 350000 & $2,0 \%$ \\
\hline Chequia & 162921 & 4934000 & $3,3 \%$ \\
\hline Dinamarca & 158961 & 2678000 & $5,9 \%$ \\
\hline Estonia & 38036 & 613000 & $6,2 \%$ \\
\hline Finlandia & 182105 & 2368000 & $7,7 \%$ \\
\hline Francia & 2372812 & 26118000 & $9,1 \%$ \\
\hline Alemania & 2635980 & 39176000 & $6,7 \%$ \\
\hline Grecia & 117516 & 3548000 & $3,3 \%$ \\
\hline Hungría & 234747 & 4176000 & $5,6 \%$ \\
\hline Irlanda & 95147 & 1899000 & $5,0 \%$ \\
\hline Italia & 1923745 & 21973000 & $8,8 \%$ \\
\hline Letonia & 19341 & 868000 & $2,2 \%$ \\
\hline Lituania & 7332 & 1301000 & $0,6 \%$ \\
\hline Luxemburgo & 25345 & 255000 & $9,9 \%$ \\
\hline Malta & 2404 & 182000 & $1,3 \%$ \\
\hline Países Bajos & 798778 & 8115000 & $9,8 \%$ \\
\hline Polonia & 365900 & 15812000 & $2,3 \%$ \\
\hline Portugal & 215963 & 4309000 & $5,0 \%$ \\
\hline Rumanía & 136385 & 8235000 & $1,7 \%$ \\
\hline Eslovaquia & 51611 & 2405000 & $2,1 \%$ \\
\hline Eslovenia & 10710 & 902000 & $1,2 \%$ \\
\hline España & 1358401 & 17717000 & $7,7 \%$ \\
\hline Suecia & 195832 & 4660000 & $4,2 \%$ \\
\hline Reino Unido & 1694710 & 30028000 & $5,6 \%$ \\
\hline TOTAL EU-28 & $\mathbf{1 3 6 2 1 5 3 5}$ & $\mathbf{2 1 5 7 2 2 0 0 0}$ & $\mathbf{6 , 3} \%$ \\
\hline
\end{tabular}

* Empleo remunerado, edades comprendidas entre 15 y 65 años, Eurostat, 2015. 
Cuadro 6. Evolución del empleo remunerado en la economía social en Europa

\begin{tabular}{|c|c|c|c|c|}
\hline & \multicolumn{3}{|c|}{ Empleo en la economía social } & \multirow[b]{2}{*}{$\begin{array}{c}\Delta \% \\
2010-2015\end{array}$} \\
\hline País & $2002 / 2003$ & $2009 / 2010$ & $2014 / 2015$ & \\
\hline Austria & 260145 & 233528 & 308050 & $31,9 \%$ \\
\hline Bélgica & 279611 & 462541 & 403921 & $-12,7 \%$ \\
\hline Bulgaria & $(\mathrm{n} / \mathrm{d})$ & 121300 & 82050 & $-32,4 \%$ \\
\hline Croacia & $(\mathrm{n} / \mathrm{d})$ & 9084 & 15848 & $74,5 \%$ \\
\hline Chipre & 4491 & 5067 & 6984 & $37,8 \%$ \\
\hline Chequia & 165221 & 160086 & 162921 & $1,8 \%$ \\
\hline Dinamarca & 160764 & 195486 & 158961 & $-18,7 \%$ \\
\hline Estonia & 23250 & 37850 & 38036 & $0,5 \%$ \\
\hline Finlandia & 175397 & 187200 & 182105 & $-2,7 \%$ \\
\hline Francia & 1985150 & 2318544 & 2372812 & $2,3 \%$ \\
\hline Alemania & 2031837 & 2458584 & 2635980 & $7,2 \%$ \\
\hline Grecia & 69834 & 117123 & 117516 & $0,3 \%$ \\
\hline Hungría & 75669 & 178210 & 234747 & $31,7 \%$ \\
\hline Irlanda & 155306 & 98735 & 95147 & $-3,6 \%$ \\
\hline Italia & 1336413 & 2228010 & 1923745 & $-13,7 \%$ \\
\hline Letonia & 300 & 440 & 19341 & $(\mathrm{n} / \mathrm{p})$ \\
\hline Lituania & 7700 & 8971 & 7332 & $-18,3 \%$ \\
\hline Luxemburgo & 7248 & 16114 & 25345 & $57,3 \%$ \\
\hline Malta & 238 & 1677 & 2404 & $43,4 \%$ \\
\hline Países Bajos & 772110 & 856054 & 798778 & $-6,7 \%$ \\
\hline Polonia & 529179 & 592800 & 365900 & $-38,3 \%$ \\
\hline Portugal & 210950 & 251098 & 215963 & $-14,0 \%$ \\
\hline Rumanía & $(\mathrm{n} / \mathrm{d})$ & 163354 & 136385 & $-16,5 \%$ \\
\hline Eslovaquia & 98212 & 44906 & 51611 & $14,9 \%$ \\
\hline Eslovenia & 4671 & 7094 & 10710 & $51,0 \%$ \\
\hline España & 872214 & 1243153 & 1358401 & $9,3 \%$ \\
\hline Suecia & 205697 & 507209 & 195832 & $-61,4 \%$ \\
\hline Reino Unido & 1711276 & 1633000 & 1694710 & $3,8 \%$ \\
\hline TOTAL EU-28 & 11142883 & 14137218 & 13621535 & $-3,6 \%$ \\
\hline
\end{tabular}

Fuente: CIRIEC/CESE

$(\mathrm{n} / \mathrm{d})$ no disponible, $(\mathrm{n} / \mathrm{p})$ no procede 


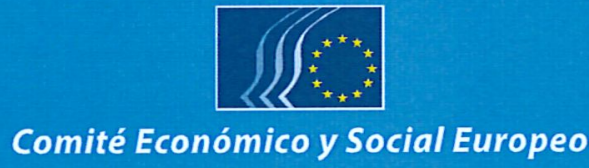

Rue Belliard/Belliardstraat 99

1040 Bruxelles/Brussel

BELGIQUE/BELGIË

Responsable editorial: Unidad de Visitas y Publicaciones

EESC-2017-104-ES

www.eesc.europa.eu

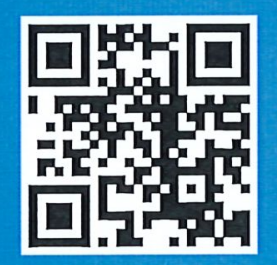

(c) Unión Europea, 2017

Reproducción autorizada, con indicación de la fuente bibliográfica.

Para cualquier uso o reproducción de las ilustraciones, hay que solicitar autorización directamente al titular de los derechos de autor.
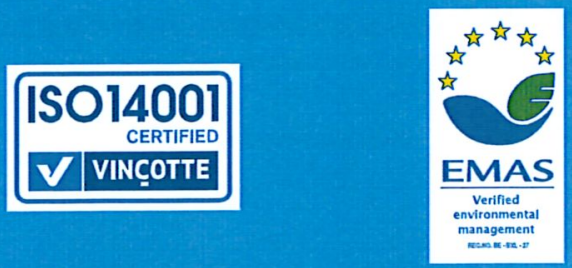
This yearly series of working papers (WP) aims to publish works resulting from the scientific network of CIRIEC. The WPs are subject to a review process and are published under the responsibility of the President of the International Scientific Council, the president of the scientific Commissions or the working groups coordinators and of the editor of CIRIEC's international scientific journal, the Annals of Public and Cooperative Economics.

These contributions may be published afterwards in a scientific journal or book.

The contents of the working papers do not involve CIRIEC's responsibility but solely the author(s') one.

The submissions are to be sent to CIRIEC (ciriec@uliege.be).

Cette collection annuelle de Working Papers (WP) est destinée à accueillir des travaux issus du réseau scientifique du CIRIEC. Les WP font l'objet d'une procédure d'évaluation et sont publiés sous la responsabilité du président du Conseil scientifique international, des présidents des Commissions scientifiques ou des coordinateurs des groupes de travail et du rédacteur de la revue scientifique internationale du CIRIEC, les Annales de l'économie publique, sociale et coopérative.

Ces contributions peuvent faire l'objet d'une publication scientifique ultérieure.

Le contenu des WP n'engage en rien la responsabilité du CIRIEC mais uniquement celle du ou des auteurs.

Les soumissions sont à envoyer au CIRIEC (iriec@uliege.be).

This working paper is indexed and available in RePEc

Ce working paper est indexé et disponible dans RePEc

ISSN 2070-8289

ISBN 978-2-931051-02-3

EAN 9782931051023

http://doi.org/10.25518/ciriec.wp201903

D/2019/1406/3-d 
WP Collection 2019

2019/01 Évolutions récentes de l'économie sociale dans l'Union européenne Rafael CHAVES \& José Luis MONZÓN

2019/02 Recent Evolutions of the Social Economy in the European Union Rafael CHAVES \& José Luis MONZÓN

2019/03 Evolución reciente de la economía social en la Unión Europea Rafael CHAVES \& José Luis MONZÓN 



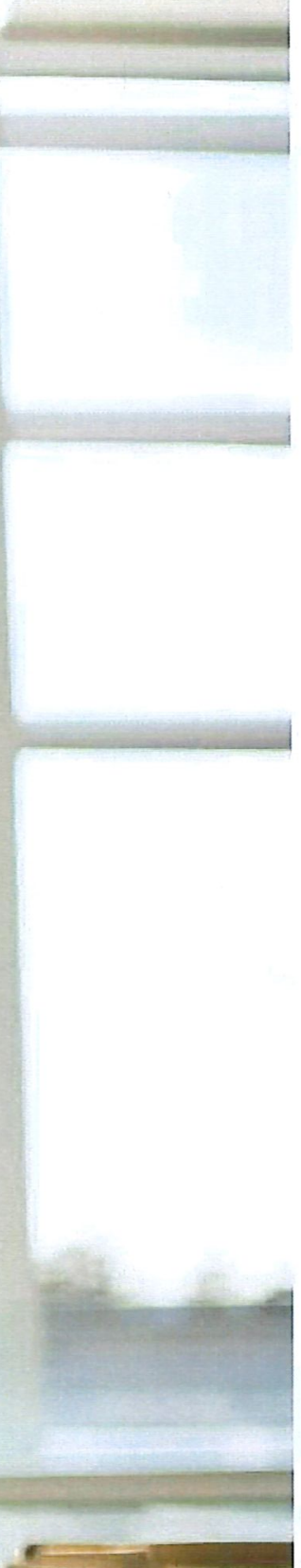

No part of this publication may be reproduced.

Toute reproduction meme partielle

de cette publication est strictement interdite.

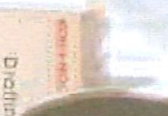

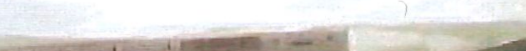


CIRIEC (International Centre of Research and Information on the Public, Social and Cooperative Economy) is a non-governmental international scientific organization.

Its objectives are to undertake and promote the collection of information, scientific research, and the publication of works on economic sectors and activities oriented towards the service of the general and collective interest: action by the State and the local and regional public authorities in economic fields (economic policy, regulation); public utilities; public and mixed enterprises at the national, regional and municipal levels; the so-called "social economy" (not-for-profit economy, cooperatives, mutuals, and non-profit organizations; etc.).

In these fields CIRIEC seeks to offer information and opportunities for mutual enrichment to practitioners and academics and for promoting international action. It develops activities of interest for both managers and researchers.

\section{Le CIRIEC (Centre International de Recherches et d'Information sur l'Economie Publique, Sociale et Coopérative) est une organisation scientifique internationale non gouvernementale.}

Ses objectifs sont dassurer et de promouvoir la collecte dinformations, la recherche scientifique et la publication de travaux concernant les secteurs économiques et les activités orientés vers le service de l'intérêt général et collectif : l'action de l'Etat et des pouvoirs publics régionaux et locaux dans les domaines économiques (politique économique. régulation) : les services publics ; les entreprises publiques et mixtes aux niveaux national, régional et local: « l'économie sociale » : coopératives, mutuelles et associations sans but lucratif : etc.

Le CIRIEC a pour but de mettre à la disposition des praticiens et des scientifiques des informations concernant ces différents domaines, de leur fournir des occasions d'enrichissement mutuel et de promouvoir une action et une réflexion internationales. Il développe des activités qui intéressent tant les gestionnaires que les chercheurs scientifiques.

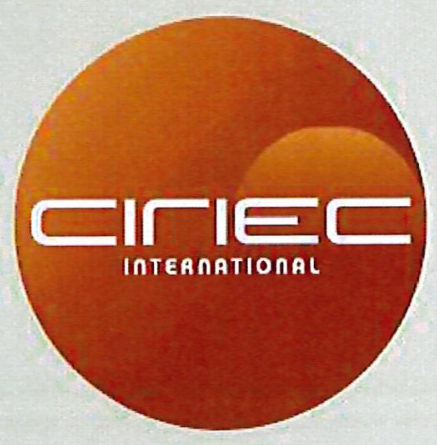

INTERNATIONAL CENTRE OF RESEARCH AND INFORMATION ON THE PUBLIC, SOCIAL AND COOPERATIVE ECONOMY - AISBL

CENTRE INTERNATIONAL DE RECHERCHES ET D'INFORMATION SUR L'ÉCONOMIE PUBLIQUE, SOCIALE ET COOPÉRATIVE - AISBL

Universitè de Llège | Quartier Agora | Place des Orateurs 1 | Bãtiment B33boite 6 | BE-40oo Llège (Belglum) | T+32(0)4366 2746 | F+32(0)43662958 ciriecoulg.ac.be / www.cirieculgac.be 